\title{
Determination of Optimum Maturity Stages of Mangoes Using Fruit Spectral Signatures
}

\author{
P. Subedi ${ }^{1}$, K. Walsh ${ }^{1}$, and P. Purdy ${ }^{2}$ \\ ${ }^{1}$ Central Queensland University, Rockhampton, Australia \\ ${ }^{2}$ Integrated Spectronics, Sydney, Australia
}

Keywords: Mango, non-invasive, fruit maturity, NIR Spectroscopy, Nirvana

\begin{abstract}
A purpose designed hand-held spectroscope ('Nirvana', Integrated Spectronics) was used to assess mango fruit pigmentation (flesh and skin) and flesh dry matter content. Fruit dry matter content and flesh colour was assessed of fruit on the tree, and used as indices of fruit maturity. Dry matter of fruit at harvest was also closely related to total soluble solids of fully ripe fruit, and thus eating quality. The calibration model was robust across growing regions for dry matter $(\mathrm{R}>0.96$ with $\mathrm{RMSECV}<0.6 \% \mathrm{DM})$, but regional models were required for flesh colour. The units were used to: (i) non-invasively monitor fruit on tree at weekly intervals from stone hardening stage, allowing a gauge of time to harvest; (ii) describe variation in fruit maturity in relation to canopy architecture, and thus inform selective picking procedures; (iii) assess average fruit maturity across blocks, allowing maturity zoning across the production area; (iv) relate dry matter content of hard green fruit to later ripening behaviour and eating quality (Brix and flavour).
\end{abstract}

\section{INTRODUCTION}

Like other fruit, eating quality in mango (Mangifera indica) is determined by a number of factors, including volatiles content. However, a base attribute is a minimum carbohydrate content. The mango fruit accumulates starch during maturation. Fruit dry matter (DM) content is an index of the total of soluble sugars and starch content of the fruit. The Australian domestic market generally requires a minimum 14\% dry matter content at harvest (Meurant et al. 1999), a specification which sets a lower limit to the Brix of the ripened mango fruit.

During ripening, starch converts to soluble sugars. Thus fruit dry matter (DM) content (sum of starch and sugars) is constant during ripening, while sugar content increases and acid content decreases. Juice ${ }^{\circ}$ Brix is a measure of the total soluble sugars content (\%TSS), with the \%TSS of ripe fruit correlated to the DM content of fruit at harvest. Retailers may set specifications on either DM or TSS. For example, Coles (www.coles.com.au) stipulate a quality standard of $14 \%$ TSS for fruit received to store.

Fruit must be physiologically mature at harvest in order to ripen properly. Fruit maturity in mango can be recognized by changes in external appearance (e.g. 
'rounding' of fruit shoulders). However, it is difficult to recognise maturity on this basis in some cultivars (e.g. Calypso). Destructive assessment of fruit maturity can be based on flesh colour or flesh DM. Visible - short wavelength near infrared spectroscopy (vis-SWNIRS) is a candidate technology for assessment of these parameters in intact fruit.

Near infrared spectroscopy (NIRS) is used successfully for rapid, nondestructive assessment of a number of plant constituents (Clark et al. 2003; Lammertyn et al. 2001). In Kensington Pride, it can be used to predict DM in justharvested fruit (Guthrie and Walsh 1997), \%TSS in ripe fruit, and \%TSS of ripe fruit can be predicted in its green stages using spectra collected at harvest stage (Subedi et al., 2007). Thus this technology offers potential for assessment of harvested fruit maturity and final eating quality, with potential application for in-field maturity assessment of fruit on the tree, and in-line assessment of final eating quality.

In this exercise, we aim to utilise handheld Vis-SWNIRS equipment to monitor mango fruit maturity while on the tree.

\section{MATERIALS AND METHODS}

'Nirvana' hand held Vis-SWNIR spectrometers (Integrated Spectronics, Sydney, Australia) were used. Units were benchmarked in terms of repeatability (on a white tile reference) and predictive performance of an apple Brix model, and were were used throughout the 2009/10 mango season in various mango production districts in Northern Territory and Queensland, Australia.

The performance of the units was compared in a range of ambient conditions (constant fruit temp, varying ambient light and gun temperature). Fruit were selected from inside and outside the canopy, and from both sides of the tree (population 1). Of these fruit, some were in full sun on the tree, and some were fully shaded fruit. Both cheeks of the fruit were scanned. Spectra were acquired while fruit were still on the tree (condition 1; during the mid/late morning). The fruit was then harvested, desapped and washed in a detergent solution (standard pack-house procedure). The desapped fruit were taken into the pack-house, with both fruit and handgun left on the bench for about $2 \mathrm{~h}$ to equilibrate in temperature (tested with IR thermometer). Spectra of the fruit were then acquired of the same positions on the fruit as before, but in pack-house shade (condition 2). Spectra were then collected of the fruit in ambient sunlight (with fruit at pack-house temperature) (condition 3). The unit was then allowed to heat for $2 \mathrm{~h}$ (to $38^{\circ} \mathrm{C}$ ) under full sunlight before spectra were again acquired in ambient sunlight (condition 4).

Spectra were also acquired of another five populations of fruit from different orchards and fruit maturation stages. Fruit were selected from trees across the orchard to maximise variation in fruit DM. A calibration model based on all data was used in prediction of DM of fruit remaining on tree and of harvested fruit following selective picking operations.

The dry matter content of fruit was determined by taking a $27 \mathrm{~mm}$ diameter, $10 \mathrm{~mm}$ deep core of fruit flesh from the equatorial part of each cheek of each fruit, after removing skin (1-2 mm thickness) using a potato peeler. Dry matter was determined by weight loss following $48 \mathrm{~h}$ drying in a forced air oven at $65{ }^{0} \mathrm{C}$. Flesh colour was assessed of the cut flesh surface using a Minolta Chromameter CR- 400 (Hunter b). 
The Unscrambler v 9.1 (Camo, Oslo, Norway) was used for partial least squares regression (PLSR) calibration model development (prediction of a given attribute from spectral data). Model performance was evaluated in terms of RMSECV and $\mathrm{R}_{\mathrm{cv}}$, and in terms of prediction of samples not included in the calibration set (RMSEP and $\mathrm{R}_{\mathrm{p}}$ ). Cross-validation was performed using 20 segments with random selection of samples.

\section{RESULTS AND DISCUSSION}

\section{Spectral Window Selection for DM and Flesh Colour}

The interactance geometry of the Nirvana spectrometer produced spectra with strong visible wavelength features, likely to be related to flesh carotenoid content and skin chlorophyll content, while the most notable feature in the SWNIR was the 970 nm O-H (water) related peak (Fig. 1). A 'moving windows' repetitive PLS approach (Guthrie et al., 2005) was used to define the optimum wavelength region for PLSR modelling. For flesh DM the optimal wavelength region was 735-975 nm, while for flesh colour the optimal wavelength region was 501-1029 nm (data not shown).

\section{Calibration and Prediction Models}

To test the performance of the unit under field conditions, spectra were collected of the same fruit under a range of environmental conditions. PLSR model performance on DM was always better than for internal flesh colour. However, model performance of flesh colour was also acceptable $\left(\mathrm{R}_{\mathrm{CV}}=0.9\right)$.

It was expected that model statistics would be similar for runs 2 and 4 (i.e. fruit at constant temperature, and packhouse shade), and that results from these runs would be superior to that of other runs (i.e. high and varying ambient light and temperature). However, PLS regression statistics were not markedly different for spectra acquired under the various environmental conditions (Table 1).

A model developed on populations 2 to 6 was used in prediction of population 1 (all data and separate conditions). Prediction results for population 1 spectra collected under different environmental conditions were similar in terms of $\mathrm{R}$ and bias (except for flesh colour for condition 4, for which bias was increased) (Table 2). Prediction of flesh colour was not as accurate as that for DM (e.g. lower R), but predictions were equally unaffected by the condition under which spectra were acquired.

\section{Modelling Ripe-stage TSS Using Green Stage Spectra}

Calibration model statistics for TSS of ripe stage fruit based on spectra recorded from hard green stage fruit were generally acceptable (RMSECV <0.76 \%TSS) (Table 3). However, prediction of ripe stage TSS from hard green stage spectra was poor across independent populations (e.g. SDR<1) (Table 4). This result is partly attributable to the low SD in these populations.

\section{Technology Application}


Several modes of application of this technology are proposed:

\section{using the technology to follow fruit maturation on tree}

In this application fruit from across an orchard was assessed using a systemic sampling method, with GPS derived location data saved along with predicted DM and FC. An interpolated graphical display of DM or FC across the orchard was then generated using the 'GeoMap' feature of the Nirvana software to assist in the identification of areas of trees that have fruit of similar maturity (Fig. 2). Subsequent management can then be targeted at these maturity zones.

Such an exercise can assist in identifying the order in which different areas should be harvested. Repeated measures over time can provide information on the rate of fruit maturation, and therefore guide a prediction of the time remaining to harvest

\section{(ii) using the technology to map fruit 'maturity' within tree}

Fruit maturity will vary within a given tree in relation to the age, canopy light conditions and aspect of the tree. Flowering events on a given tree can be quite uniform for small canopy trees, and quite variable in trees with large, untrained canopies. Assessment of this variation is essential to (a) provide information to picking crews, and (b) guide the design of sampling and harvesting strategies (e.g. strip picking versus selective picking).

\section{(iii) using the technology to check/train pickers}

In the orchards where selective picking is employed, the handheld spectroscopic systems can effectively be used to train harvesting crews (Fig. 4). Training given to pickers on the recognition of mature fruit is often temporary in effect, with percentage falling within a single day from a morning training event. As an objective assessment system, use of the handheld units can assist in reinforcing the training message.

\section{(iv) using the technology to target selective markets}

Lot analysis of DM content in (hard green) fruit at harvest can be used to differentiate fruit with higher eating quality (higher TSS) when fully ripened, allowing for differential marketing.

\section{CONCLUSION}

The results indicate that information obtained from short wavelength spectral signature can utilised to monitor fruit maturity on the tree, in the packing shed and ripe stage eating quality of a fruit can be predicted in its green stages. Therefore the technology has a potential for use as a monitoring tool for a production specific harvest management. However, the equipment should be re-calibrated to cope with change in fruit composition due to change in production factors (e.g. husbandry and climate) and tree physiology. 


\section{ACKNOWLEDGEMENT}

We thank Horticulture Australia Ltd., Hortical P/L, Colour Vision Systems P/L, Integrated Spectronics $\mathrm{P} / \mathrm{L}$ and OneHarvest for support of related activity.

\section{REFERENCES}

Clark, C. J; McGlone, V. A.; Requejo, C; White, A. and Woolf, A. B. (2003). Dry matter determination in 'Hass' avocado by NIR spectroscopy. Journal of Postharvest Biology and Technology. 29, 301 - 308.

Guthrie, J.A. and Walsh, K.B., (1997). Non-invasive assessment of pineapple and mango fruit quality using near infrared spectroscopy. Australian Journal of Experimental Agriculture 37, 253-263.

Guthrie, J.A., Walsh, K.B., Reid, D.J., Liebenberg, C.J., (2005). Assessment of internal quality attributes of mandarin fruit. 1 . NIR calibration model development. Australian Journal of Agricultural Research. 56, 405-416.

Lammertyn, J., 2001. A Respiration-Diffusion Model to Study Core Breakdown in Conference Pears. Ph.D. Dissertation, Katholieke, Universiteit Leuven, Leuven.

Meurant, N; Kernot, I; Holmes, R; MacLeod N; Fullelove, G and Bally, I (Eds.) (1999) 'Mango Information Kit' (Queensland Department of Primary Industries, Brisbane, Australia).

Subedi, P.P; Walsh, K.B. and Owens, G. (2007). Prediction of mango eating quality at harvest using short-wave near infrared spectroscopy. Journal of Postharvest Biology and Technology. 43, $326-334$. 


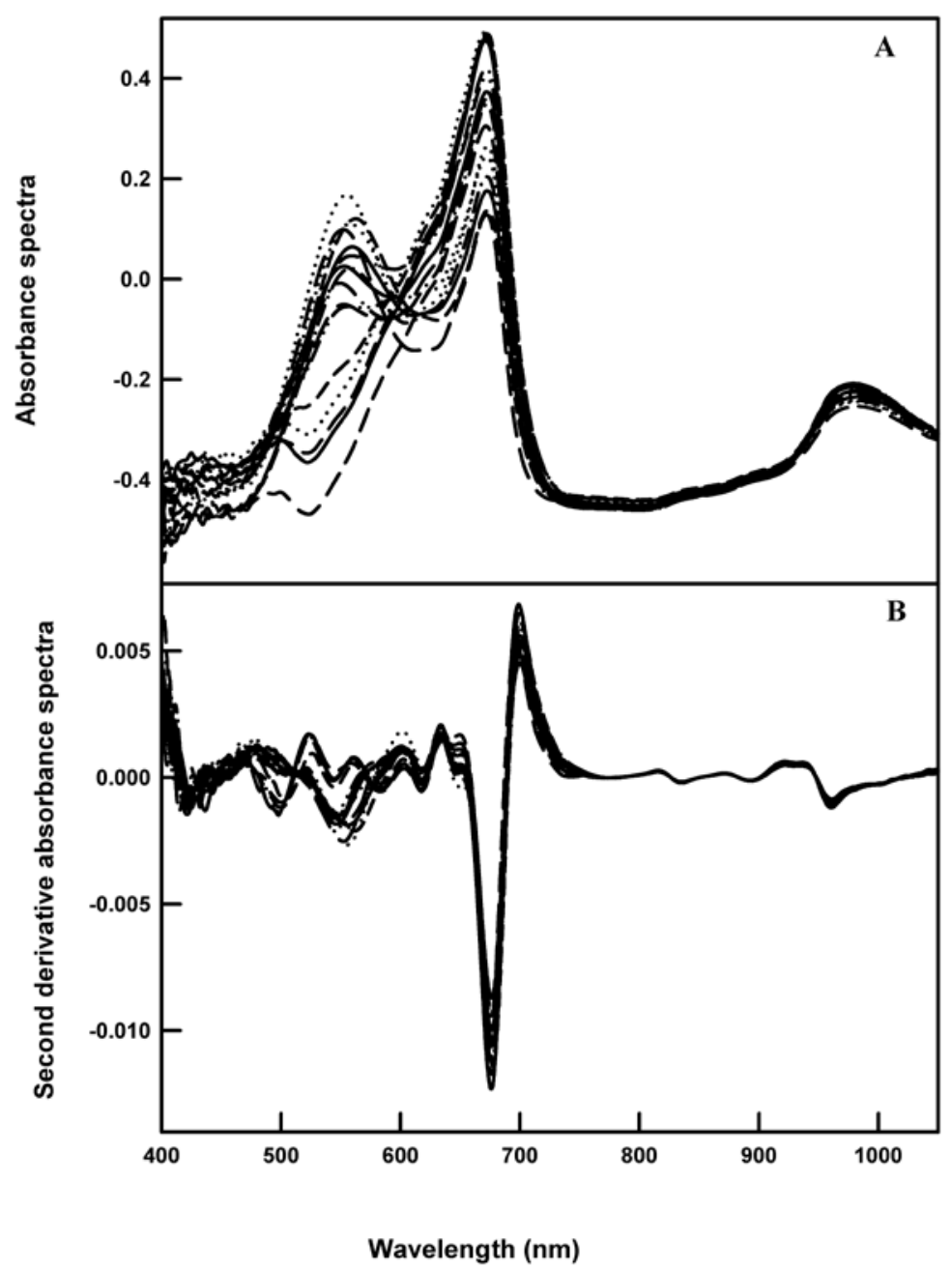

Figure 1. Absorbance (top panel) and second derivative of absorbance spectra of intact mango fruit of a range of maturities collected using interactance optics (Nirvana unit). 


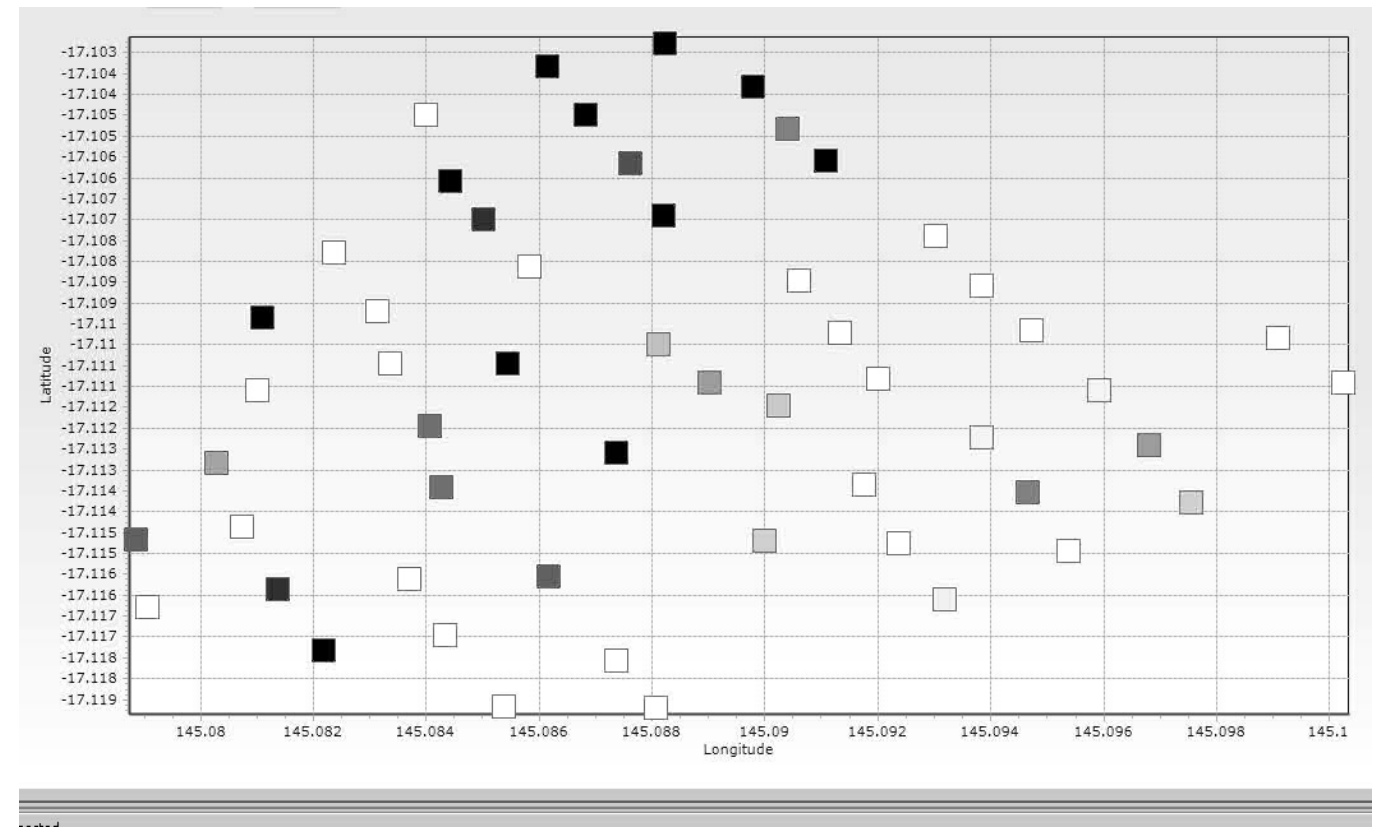

Figure 2. Example output from the Integrated Spectronics Nirvana 'Yieldmap' feature, with gray scale coding on sample location representing fruit DM (with darker colour representing higher DM). 


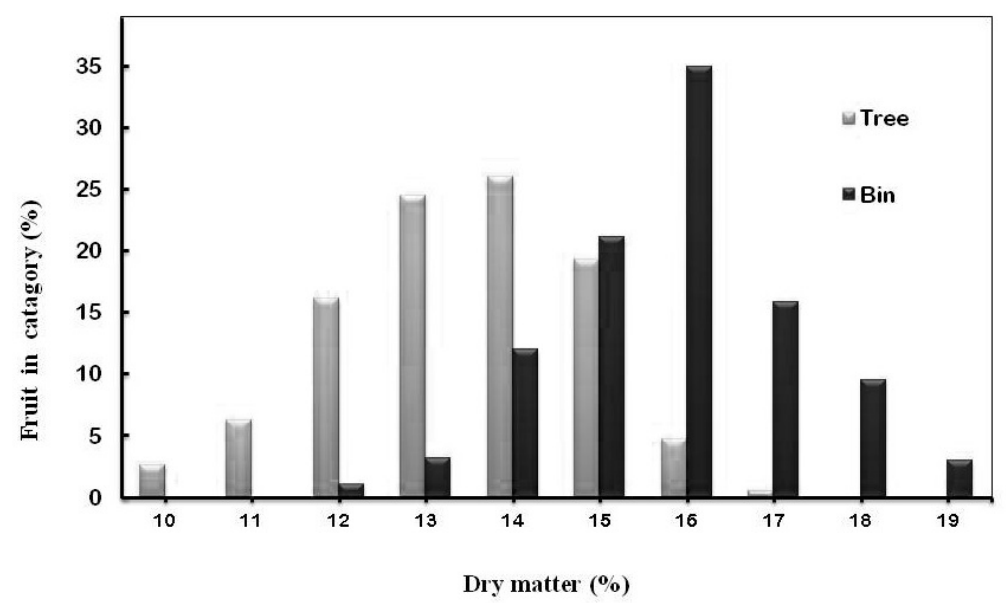

Figure 3. Dry matter distribution of fruit on the trees and in the harvest bin useful information for reinforcing training of picking crews. 


\section{Tables}

Table 1. Calibration model statistics on mango dry matter (DM) and flesh colour (FC), assessed under various environmental conditions. Spectra were acquired using a Nirvana spectrometer of a set of fruit (population 1), with spectra collected of fruit on the tree (Condition 1); of fruit in packhouse shade (Condition 2), of fruit at packhouse temperature but in ambient sunlight (Condition 3) and of fruit allowed to heat to $38^{\circ} \mathrm{C}$ and with spectra collected in full sunlight (Condition 4). The mean and standard deviation of fruit DM and FC was $16.2 \pm 2.78$ and $5.33 \pm 1.74 \%$, respectively.

\begin{tabular}{crrrrr}
\hline \multirow{2}{*}{ Attribute } & Condition & $\mathrm{n}$ & $\begin{array}{c}\# \\
\text { Factors }\end{array}$ & $\mathrm{R}_{\mathrm{CV}}$ & RMSECV \\
\hline \% DM & 1 & 100 & 7 & 0.95 & 0.89 \\
& 2 & 100 & 7 & 0.95 & 0.85 \\
& 3 & 100 & 7 & 0.96 & 0.76 \\
& 4 & 100 & 6 & 0.94 & 0.83 \\
& $1-4$ & 400 & 7 & 0.96 & 0.78 \\
\hline FC & 1 & 100 & 4 & 0.90 & 0.81 \\
& 2 & 100 & 3 & 0.90 & 0.79 \\
& 3 & 100 & 4 & 0.88 & 0.80 \\
& 4 & 100 & 4 & 0.88 & 0.78 \\
& $1-4$ & 400 & 6 & 0.90 & 0.76 \\
\hline
\end{tabular}

$\mathrm{R}_{\mathrm{cv}}=$ correlation coefficient of cross validation, $\mathrm{RMSECV}=$ root mean square error of cross validation. 
Table 2. Prediction performance on mango fruit dry matter and internal flesh colour assessed using models developed on data of populations 2 to 6 (calibration set), in prediction of population 1 (subset conditions, and all data) (see Table 1). The calibration set possessed a mean and standard deviation (SD) of $15.84 \pm 1.85$ and 5.67 \pm 1.28 for DM and FC, respectively, with a $\mathrm{R}_{\mathrm{cv}}$ of 0.92 and RMSECV of 0.75 , with $\mathrm{n}$ $=1319$, for DM, and a $R_{\mathrm{cv}}$ of 0.81 and RMSECV of 0.72 , with $\mathrm{n}=1113$, for $\mathrm{DM}$ and FC, respectively

\begin{tabular}{|c|c|c|c|c|c|c|}
\hline Attribute & Pred set & Population & $\mathrm{R}_{\mathrm{p}}$ & RMSEP & SDR & Bias \\
\hline \multirow[t]{5}{*}{$\% \mathrm{DM}$} & Con. 1 & 100 & 0.95 & 0.95 & 2.93 & 0.84 \\
\hline & Con. 2 & 100 & 0.95 & 0.86 & 3.23 & 0.86 \\
\hline & Con. 3 & 100 & 0.95 & 0.87 & 3.20 & 0.86 \\
\hline & Con. 4 & 100 & 0.94 & 0.83 & 3.35 & 0.90 \\
\hline & Con. 1-4 & 400 & 0.95 & 0.89 & 3.12 & 0.85 \\
\hline \multirow[t]{5}{*}{$\mathrm{FC}$} & Con. 1 & 100 & 0.85 & 1.13 & 1.54 & 0.39 \\
\hline & Con. 2 & 100 & 0.84 & 1.25 & 1.39 & 0.30 \\
\hline & Con. 3 & 100 & 0.84 & 1.11 & 1.60 & 0.16 \\
\hline & Con. 4 & 100 & 0.85 & 1.35 & 1.29 & 0.82 \\
\hline & Con. 1-4 & 400 & 0.82 & 1.22 & 1.43 & 0.34 \\
\hline
\end{tabular}

$\mathrm{R}_{\mathrm{p}}=$ Correlation coefficient of prediction, RMSEP = root mean square error of prediction, SDR = SD/RMSEP. 
Table 3. Partial least squares regression (PLSR) calibration model statistics, for models based on second derivative of absorbance spectra from fruit harvested at hard green stage, against the attribute of \% total soluble solids content of the same fruit when fully ripened.

\begin{tabular}{lllllll}
\hline Population & $\begin{array}{l}\text { Sample } \\
\#\end{array}$ & Mean & SD & \# Factor & $\mathrm{R}_{\mathrm{cv}}$ & RMSECV \\
\hline & & & & & & \\
7 & 188 & 13.48 & 0.96 & 7 & 0.86 & 0.49 \\
8 & 165 & 11.67 & 0.77 & 7 & 0.85 & 0.40 \\
9 & 165 & 12.74 & 1.17 & 8 & 0.90 & 0.50 \\
\hline
\end{tabular}


Table 4. PLSR prediction model statistics for Brix of ripe stage fruit using spectra of hard green stage fruit using a handheld Nirvana unit.

\begin{tabular}{ccccccccc}
\hline Population & Sample \# & Mean & SD & \#Factor & R & RMSEP & SDR & Bias \\
\hline 7 & 188 & 13.48 & 0.96 & 5 & 0.83 & 1.06 & 0.72 & 0.92 \\
8 & 165 & 11.67 & 0.77 & 5 & 0.74 & 0.63 & 0.66 & 0.33 \\
9 & 165 & 12.74 & 1.17 & 7 & 0.73 & 0.86 & 0.59 & 0.68 \\
\hline
\end{tabular}

$\mathrm{SD}=$ standard deviation, Factors $=$ number of principle components, $\mathrm{R}=$ correlation coefficient, RMSECV = root mean square error of cross validation, $\mathrm{SDR}=$ SD/RMSECV. 